https://nv.nltu.edu.ua

https://doi.org/10.15421/40281020

$@ \square$ Correspondence author

Article received $15.10 .2018 \mathrm{p}$.

Article accepted 29.11.2018 p.

I. Yu. Popadyuk

удк 66.06:532.529

popaduk_i@ukr.net

I. Ю. Попадюк, Б. С. Піцишин, В. І. ОреЛ

Національний університет "Львівська політехніка", м. Львів, Украйна

\title{
ЗБІЛЬШЕННЯ ТЕРТЯ У ПОТОЦІ ТЕЙЛОРА-КУЕТТА ПІД ЧАС ВИКОРИСТАННЯ НАТРІЙ КАРБОКСИМЕТИЛЦЕЛЮЛОЗИ
}

\begin{abstract}
Представлено результати експериментальних досліджень впливу ексцентриситету ротора відносно статора та розчинів карбоксиметилцелюлози на коефіцієнт тертя в гідрогальмі з регулювальним гальмівним моментом. Кільцевий проміжок між ротором із діаметром 113 мм і статором із діаметром 142 мм заповнювали водними розчинами карбоксиметилцелюлози 3 додаванням гідрокарбонату натрію для стабілізації. Масові концентрації карбоксиметилцелюлози - 0,5; 1,0; 2,0; 4,0 \%, гідрокарбонату натрію - 0,2 \% від маси розчину. Кільцевий проміжок між поверхнями циліндрів, який відповідав коаксіальному їх розташуванню, трансформувався у замкнений конфузорно-дифузорний внаслідок зміни положення зовнішнього циліндра відносно внутрішнього. Виявлено залежність коефіцієнта тертя від числа Рейнольдса, ширини проміжку між ротором і статором під час їх аксіального розташування та концентрації водних розчинів карбоксиметилцелюлози. Зі збільшенням числа Рейнольдса спостережено зменшення коефіцієнта тертя для досліджених концентрацій розчинів карбоксиметилцелюлози. За сталих значень числа Рейнольдса зі збільшенням концентрації розчинів карбоксиметилцелюлози отримано збільшення коефіцієнта тертя, порівняно з водою. У разі зменшення ширини проміжку одержано збільшення коефіцієнта тертя для всіх досліджених концентрацій розчинів карбоксиметилцелюлози. Отримані результати свідчать про можливість регулювання гальмівного моменту гідрогальма змінюванням ексцентриситету між ротором і статором, які можна використати під час проектування гідравлічних гальм із регулювальним гальмівним моментом.
\end{abstract}

Ключові слова: гідравлічне гальмо; ексцентричні циліндри; ротор; коефіцієнт тертя; крутний момент; число Рейнольдса.

Вступ. Випробування двигунів з метою поліпшення конструкції, підвищення експлуатаційної надійності, зменшення втрат і збільшення коефіцієнта корисної дії проводять за допомогою навантажень, які створюють гідравлічними гальмами (Pitsyshyn, 2000; Cherniuk, 1995).

У практиці гідравлічні гальма набули значного поширення під час стендових досліджень внаслідок простоти конструкції, великої енергоємності та необхідного регулювання щодо навантаження й обертів валів. Внаслідок використання гідравлічних гальм, потужність, що iï розвиває досліджуваний двигун, витрачається на подолання сил гідродинамічного опору тертя ротора в робочій рідині та переводиться в теплову енергію.

Багато дослідників, починаючи з Рейнольдса і Жуковського, досліджували рух рідини у внутрішньому просторі між коаксіальними (концентричними) чи аксіальними (ексцентричними) циліндрами, що обертаються (Cowin, 1974; Gu \& Fahidi 1985; Marcus et al., 1982; Raghupathi \& Ramachandra, 1983). Незважаючи на видиму простоту явища, задачу можна теоретично добре розв'язати лише для ламінарного режиму течії. У разі переходу до турбулентності структура таких потоків ускладнюється. Зокрема для тривимірного потоку (потік Куетта) між двома концентричними циліндрами, що обертаються окремо один від одного, спостерігаємо чотири різні нехаотичні рухи, що змінюють один одного зі збільшенням числа Рейнольдса: ламінарна течія; осесиметричні вихори Тейлора; одна азимутальна "мандруюча" хвиля, що утворюється на вихорах Тейлора; те ж саме, дві хвилі. Причому, коли потік має такі хвилі, його стан $\epsilon$ метастабільним, i одне лише число Рейнольдса не визначає, який конкретно стан має місце. Характеристики потоку залежать тоді ще й від його попереднього стану (Povh \& Chernyuk, 1986).

Цікавим випадком течії рідин у замкненому проміжку між ротором і статором $\epsilon$ циркуляція розчинів гідродинамічно активних додатків (ГДАД). Такі потоки стаються в бурильних установках (Uner et al., 1989), підшипниках (White Scott, 1989; Khonsari \& Brewe, 1994), колоїдних млинах (White Scott, 1989) тощо.

У літературі наведено дослідження течії рідин із ГДАД між концентричними циліндрами, дисками чи сферами. Ми знаємо роботи (Jones, 1988; Koeltzsch et al., 2003), де досліджено вплив ГДАД у течії між ексцентричними циліндрами. Також відомо дослідження із зменшення тертя у потоці Тейлора-Куетта під час використання різних ГДАД (Pallavi et al., 2017; Hong et al., 2010; Abdulbari et al., 2013; Abdulbari et al., 2012). У переважній більшості відомих робіт проведено матема-

Інформація про авторів:

Попадюк Ігор Юрійович, канд. техн. наук, доцент, кафедра гідравліки і сантехніки. Email: popaduk_i@ukr.net

Піцишин Богдан Степанович, ст. викладач, кафедра гідравліки і сантехніки. Email: pbsgs@ukr.net

Орел Вадим Ігорович, канд. техн. наук, доцент, кафедра гідравліки і сантехніки. Email: vadim_orel@yahoo.com

Цитування за ДСтУ: Попадюк І. Ю., Піцишин Б. С., Орел В. І. Збільшення тертя у потоці Тейлора-Куетта під час використання натрій карбоксиметилцелюлози. Науковий вісник НлтУ України. 2018, т. 28, № 10. С. 96-100.

Citation APA: Popadyuk, I. Yu., Pitshishin, B. S., \& Orel, V. I. (2018). Increase in friction in the Taylor-Coette flow using sodium carboxymethyl cellulose. Scientific Bulletin of UNFU, 28(10), 96-100. https://doi.org/10.15421/40281020 
тичний експеримент, в іншій - фізичний.

Дослідження впливу ГДАД на коефіцієнт тертя пов'язано з можливістю регулювання втрат енергії на гідравлічне тертя, що відбувається в гідрогальмі з регулювальним гальмівним моментом (Chernyuk et al., 1991). У ньому використано енергоощадний спосіб регулювання гальмівного моменту змінюванням ексцентриситету ротора в робочій рідині з ГДАД. Цей спосіб вирізняється малими габаритами й енергоємністю приводу статора і призводить до довільного розташування вала ротора в просторі. Гідравлічний опір ротора в рідині з ГДАД змінюють переміщенням статора, створюючи замкнений кільцевий конфузорно-дифузорний проміжок між ними. У потоці між ексцентричними циліндрами можливе збільшення втрат енергії по аналогії з течією в конічних конфузорах (Povh \& Chernyuk, 1989) і дифузорах (Uner et al., 1989).

Мета роботи - експериментально дослідити вплив ексцентриситету ротора відносно статора та розчинів карбоксиметилцелюлози на коефіцієнт тертя в гідрогальмі з регулювальним гальмівним моментом.

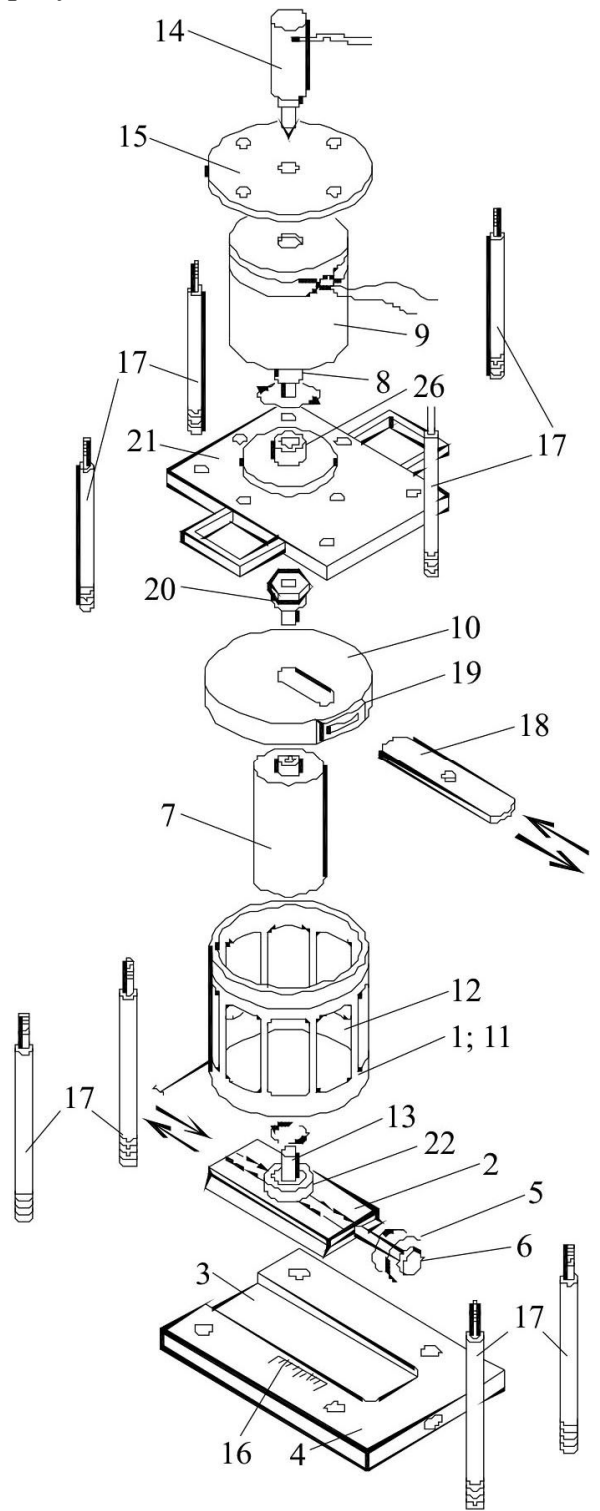

Рис. 1. Деталювальна схема експериментального стенду: 1) статор; 2) плита рухома; 3) паз; 4) плита опорна; 5) гвинт; 6) ручка; 7) ротор; 8) вал; 9) електродвигун; 10) кришка; 11) металевий каркас; 12) прозорий циліндр; 13) вісь; 14) тахометр; 15) плита; 16) шкала; 17) стойка; 18) ущільнювальна пластина; 19) ущільнення; 20) проміжна втулка; 21) плита; 22) обойма
Матеріали та методика дослідження. Експериментальний стенд. Фізичний експеримент проводили на модернізованому, порівняно 3 (Cherniuk \& Pitsyshyn, 1996), експериментальному стенді (рис. 1). Внутрішній циліндр (ротор) жорстко з'єднаний з валом електродвигуна постійного струму, закріпленого на опорній плиті, обертався 3 кутовою швидкістю $\Omega_{\mathrm{i}}=5-500$ хв$^{-1}$. Зовнішній циліндр, встановлений $з$ можливістю радіального зворотно-поступального руху, заповнювали робочою рідиною. Висота зовнішнього циліндра $-H=15,3 \mathrm{~cm}$. Діаметр зовнішнього циліндра - $D=142$ мм, внутрішнього $-d=113$ мм. Поверхня циліндрів є гладкою, матеріал неіржавіюча сталь.

Кільцевий проміжок між поверхнями циліндрів, який відповідав концентричному їх розташуванню, трансформувався у замкнений конфузорно-дифузорний під час зміни положення зовнішнього циліндра (рис. 2).

Досліди проводили за відносної ширини проміжку $b_{e} / b_{k}$, яку змінювали в межах від 0,11 до 1,0 , де індекси " $e$ " та "к" відповідають ексцентричному та концентричному розташуванню циліндрів, а $b_{e}$ - ширина конфузорно-дифузорного проміжку в найвужчому його місці (див. рис. 2). Частота обертання внутрішнього циліндра була в межах $21 \ldots 272$ об./хв. Її регулювали зміною напруги електродвигуна та вимірювали тахометром.

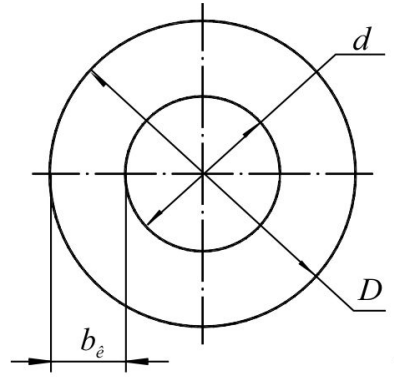

a)

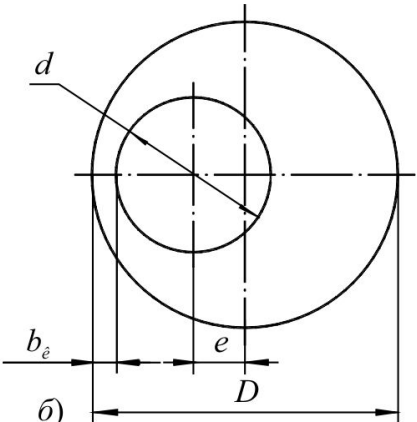

Рис. 2. Схеми розташування ротора та статора: $a$ ) коаксіальне; б) аксіальне; $e$ - ексцентриситет; $b_{\kappa}$ - ширина проміжку за коаксіального розташування ротора, $b_{e}-$ за ексцентричного

Вибір робочої рідини. Робочою рідиною бути водні розчини натрій карбоксиметилцелюлози (КМЦ) 3 додаванням $\mathrm{NaHCO}_{3}$ для стабілізації. Масові концентрації КМЦ - 0,5; 1,0; 2,0; 4,0 \%, $\mathrm{NaHCO}_{3}-0,2 \%$ від маси розчину. Концентрації визначали за вмістом у розчині безводної речовини КМЦ. Використовували клей КМЦ (ТУ.У.24.6.-251011682007-2002).

Розрахункові формули. Безрозмірний крутний момент на внутрішньому циліндрі в проміжку між ротором та статором обчислювали за формулою (Pallavi et al., 2017):

$$
G=\frac{T}{\rho v^{2} L},
$$

де: $T$ - крутний момент; $\rho$ - питома маса рідини; $v$ - кінематична в'язкість; $L$ - довжина внутрішнього циліндра.

Коефіцієнт тертя у проміжку між ротором та статором визначаємо за формулою (Pallavi et al., 2017):

$$
c_{f}=\frac{G}{\mathrm{Re}^{2}} .
$$

Число Рейнольдса, що характеризує режим течії рідини в проміжку між ротором та статором, визначаємо за формулою (Pallavi et al., 2017): 


$$
\mathrm{Re}=\frac{\Omega_{i} r_{i}\left(r_{o}-\mathrm{r}_{i}\right)}{v},
$$

де: $\Omega_{i}$ - кутова швидкість внутрішнього циліндра, $v-$ кінематична в'язкість, $r_{i}$ - радіус внутрішнього циліндра, $r_{o}$ - радіус зовнішнього циліндра.

Відносну зміну коефіцієнта тертя обчислюємо за формулою:

$$
D R=\frac{c_{f, \omega}-c_{f, s}}{c_{f, \omega}} \cdot 100, \%,
$$

де: $c_{f, \omega}-$ коефіцієнт тертя у проміжку між ротором та статором під час течії води; $c_{f, s}-$ те саме, під час течії водних розчинів КМЦ.

Обговорення отриманих результатів. На рис. 3 представлено результати експериментальних досліджень впливу води та водних розчинів КМЦ із концентраціями $C=0,5 ; 1,0 ; 2,0 ; 4,0 \%$ на безрозмірний крутний момент ротора для $b_{e} / b_{\kappa}=1,0$ за різних значень кутової швидкості. Кожна точка $є$ середнім значенням трьох повторюваних вимірювань. Зі збільшенням кутової швидкості різниця між безрозмірним крутним моментом для води та для водних розчинів КМЦ зростає. Найчіткіше це виражено для водних розчинів КМЦ концентрацією $C=4 \%$. Це добре узгоджується 3 результатами, отриманими в (Pitsyshyn \& Orel, 2009).

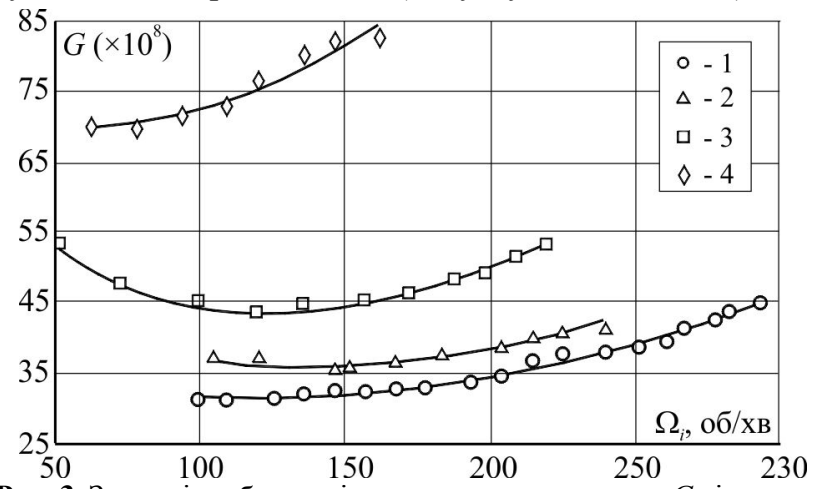

Рис. 3. Залежність безрозмірного крутного моменту $G$ від кутової швидкості $\Omega_{i}$ обертання внугрішнього циліндра для води (1) та водних розчинів КМЦ масовими концентраціями $C=1,0 \%$ (2); $2,0 \%$ (3); 4,0 \% (4) за відносної ширини проміжку $b_{e} / b_{\kappa}=1,0$

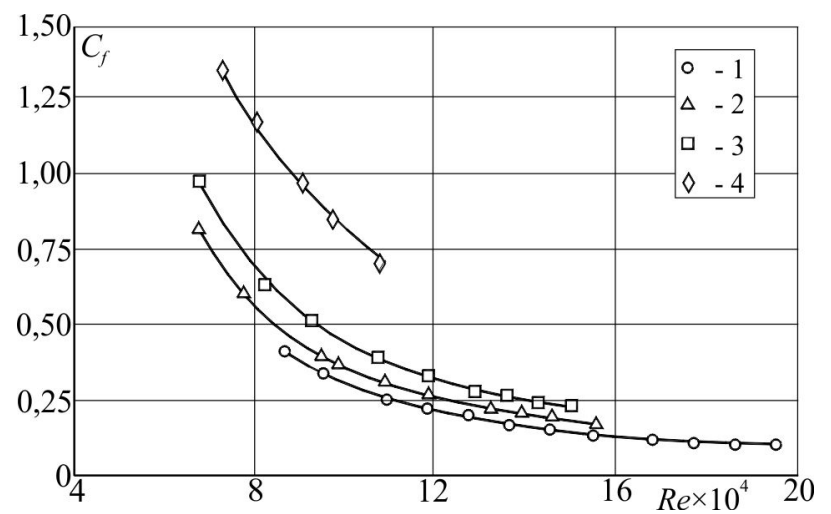

Рис. 4. Залежність коефіцієнта тертя $C_{f}$ у проміжку між ротором та статором від числа Рейнольдса $R e$ для води (1) та водних розчинів КМЦ масовими концентраціями $C=1,0 \%$ (2); $2,0 \%$ (3); 4,0 \% (4) за відносної ширини проміжку $b_{e} / b_{\kappa}=1,0$

На рис. 4 подано результати зміни коефіцієнта тертя для водних розчинів КМЦ зазначених вище концентрацій, порівняно з водою від числа Рейнольдса за відносної ширини проміжку $b_{e} / b_{\kappa}=1,0$. Зі збільшенням числа Рейнольдса спостерігаємо зменшення коефіцієнта тертя для всіх концентрацій КМЦ. Для фіксованих значень числа Рейнольдса одержано збільшення коефіцієнта тертя досліджених розчинів, порівняно 3 водою. Найбільш помітно це $\epsilon$ для концентрації $4 \%$, що узгоджується $з$ результатами, отриманими в (Pitsyshyn \& Orel, 2008).

За ексцентричного розташування ротота і статора досліджено такі значення відносної ширини проміжку $b_{e} / b_{\kappa}=0,11 ; 0,41 ; 0,70$. На рис. 5 показано залежність $C_{f}=f(\mathrm{Re})$ для води і водних розчинів КМЦ із масовими концентраціями 1,$0 ; 2,0 ; 4,0 \%$ при $b_{e} / b_{\kappa}=0,41$. Можна бачити, що експериментальні точки як для води, так і для водних розчинів КМЦ обмежуються однією твірною, від якої потім відгалужуються криві для відповідних концентрацій. Аналогічно спостерігаємо при $b_{e} / b_{\kappa}=$ 0,11 та 0,70. За цього зменшення ширини проміжку одержано збільшення коефіцієнта тертя як для води, так і для водних розчинів КМЦ.

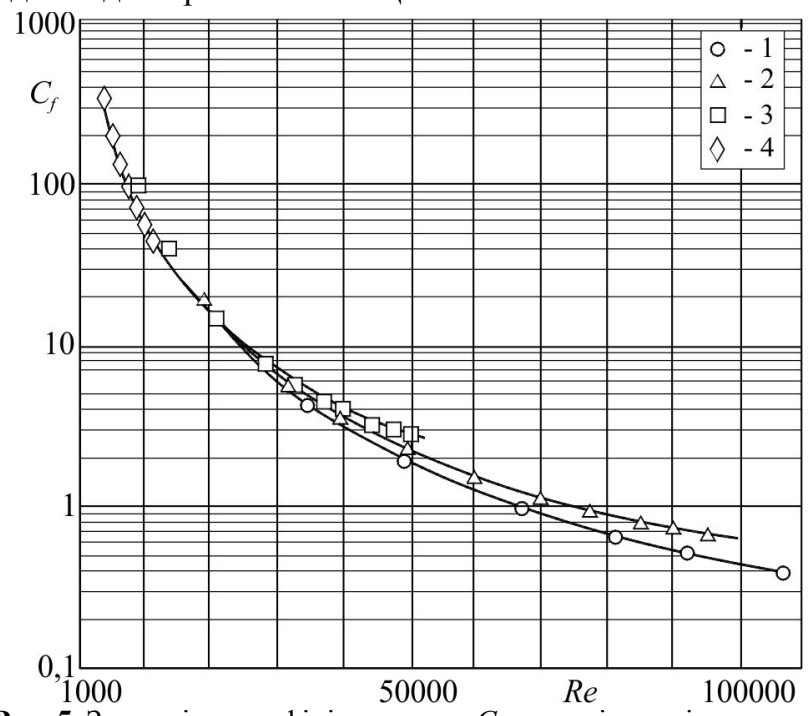

Рис. 5. Залежність коефіцієнта тертя $C_{f}$ у проміжку між ротором та статором від числа Рейнольдса $R e$ для води (1) та водних розчинів КМЦ масовими концентраціями $C=1,0 \%$ (2); $2,0 \%$ (3); 4,0 \% (4) за відносної ширини проміжку $b_{e} / b_{\kappa}=0,41$

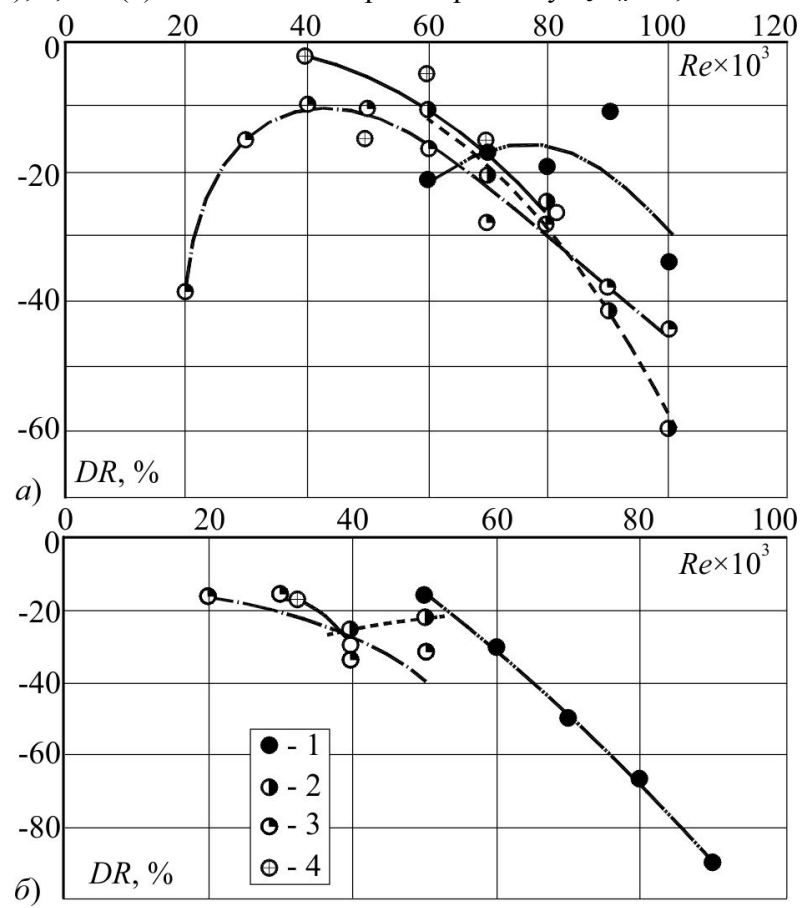

Рис. 6. Залежність відносної зміни коефіцієнта тертя $D R, \%$ за відносної ширини проміжку $b_{e} / b_{\kappa}=1$ (1); 0,7 (2); 0,41 (3); 0,11 (4) для водних розчинів КМЦ з масовими концентраціями $C=$ $1 \%(a)$ та 2,0 \% (б) від числа Рейнольдса 
На рис. 6 подано залежності відносної зміни коефіцієнта тертя за різних значень відносної ширини проміжку $b_{e} / b_{\kappa}$ для водних розчинів КМЦ із масовими концентраціями 1 та 2,0\% від числа Рейнольдса. Перехід від концентричності ротора відносно статора до його ексцентричності зсуває максимум кривої $D R=f(\mathrm{Re})$ на менші значення чисел Рейнольдса. Максимум кривої відповідає найменшому збільшенню відносної зміни коефіцієнта тертя. Відносна ширина проміжку не значно впливає на збільшення відносної зміни коефіцієнта тертя. Найбільші відносні зміни коефіцієнта тертя для концентрації $1 \%$ одержано при $b_{e} / b_{\kappa}=0,41$, а для концентрації $2 \%-$ при $b_{e} / b_{\kappa}=1,0$.

Висновки. Виявлено залежність коефіцієнта тертя від числа Рейнольдса, ширини проміжку між ротором і статором та концентрації водних розчинів КМЦ. Зі збільшенням числа Рейнольдса спостерігаємо збільшення коефіцієнта тертя для досліджених концентрацій розчинів КМЦ. За сталих значень числа Рейнольдса зі збільшенням концентрації досліджених розчинів КМЦ отримано збільшення коефіцієнта тертя, порівняно з водою. У разі зменшення ширини проміжку одержано збільшення коефіцієнта тертя для всіх досліджених концентрацій розчинів КМЦ. Відносна зміна коефіцієнта тертя має екстремальний характер. При цьому значення екстремуму відповідає найменшому збільшенню коефіцієнта тертя.

Отримані результати вказують на можливість регулювання гальмівного моменту гідрогальма змінюванням ексцентриситету між ротором і статором.

\section{Перелік використаних джерел}

Abdulbari, H. A., Shabirin, A., \& Abdurrahman, H. N. (2013). Biopolymers for improving liquid flow in pipelines - A review and future work opportunities. Journal of Industrial and Engineering Chemistry, 20(4), 1157-1170. https://doi.org/10.1016/j.jiec.2013.07.050

Abdulbari, H., Kamarulizam, N., \& Nour, A. H. (2012). Grafted natural polymer as new drag reducing agent: An experimental approach. Chemical Industry and Chemical Engineering Quarterly, 18, 361371.

Cherniuk, V. V. (1995). Hidrohalmo z rehuliuvalnym zatrymnym momentum. Bulletin of the State University "Lviv Polytechnic". Series. Teploenerhetyka. Inzheneriia dovkillia. Avtomatyzatsiia, 291, 54 63. [In Ukrainian].

Cherniuk, V. V., \& Pitsyshyn, B. S. (1996). Ustanovka dlia doslidzhennia struktury potoku ridyny mizh nespivvisnymy rotorom i statorom. Bulletin of the National University "Lviv Polytechnic". Series: Teploenerhetyka. Inzheneriia dovkillia. Avtomatyka, 304, 80-84. [In Ukrainian].

Chernyuk, V. V., Pasichnyuk, A. S., \& Gnativ, R. M. (1991). A.s. 1618912 SSSR, M.kl.3 F 16D 57/00. Sposob regulirovaniya tor- moznogo momenta gidrotormoza i gidrotormoz s reguliruemyim tormoznyim momentom. SSSR. N 4457805/27. Zayavleno 11.07.88. Opubl. 07.01.91. Byul. 1. Otkryitiya. Izobreteniya, 1, 98. [In Ukrainian].

Cowin, S. C. (1974). The theory of polar fluids. Advances in Applied Mechanics, 14, 279-347.

Gu, Z. H., \& Fahidi, T. Z. (1985). Visualization of flow patterns in axial flow between horizontal coaxial rotating cylinders. The Canadian Journal of Chemical Engineering 63(1), 14-21. https://doi.org/10.1002/cjce.5450630104

Hong, C. H., Zhang, K., Choi, H. J., \& Yoon, S. M. (2010). Mechanical degradation of polysaccharide guar gum under turbulent flow. Journal of Industrial and Engineering Chemistry, 16, 178-180. https://doi.org/10.1016/j.jiec.2009.09.073

Jones, W. M. (1988). The effect of weak elasticity on Couette flow between rotating cylinders; (1) spiral flow; (2) eccentric cylinders. Journal of Non-Newtonian Fluid Mechanics, 28(2), 255-263.

Khonsari, M. M., \& Brewe, D. E. (1994). Effect of viscous dissipation on the lubrication characteristics of micropolar fluids. Acta mech. 105(1-4), 57-58.

Koeltzsch, K., Qi., Y., Brodkey, R. S., \& Zakin, J. L. (2003). Drag reduction using surfactants in a rotating cylinder geometry. Experiments in Fluids, 34(4), 515-530. https://doi.org/10.1088/1742-6596/318/8/082016

Marcus, Ph. S., Orszag, S. A., \& Patera, A. T. (1982). Simulation of cylindrical Couette flow. Lecture Notes in Physics, 170.

Pallavi Bhambri, Ravin Narain, \& Brian Fleck. (2017). Drag Reduction Using Polysaccharides in a Taylor-Couette Flow. Polymers, 9, 683.

Pitsyshyn, B. S. (2000). Hidravlichni halma. Bulletin of the State University "Lviv Polytechnic". Series: Teploenerhetyka. Inzheneriia dovkillia. Avtomatyzatsiia, 404, 3-9. [In Ukrainian].

Pitsyshyn, B. S., \& Orel, V. I. (2008). Zastosuvannia mishalky z tsylindrychnym rotorom dlia pryhotuvannia polimernykh rozchyniv $\mathrm{z}$ metoiu vykorystannia pry hasinni pozhezh. Bulletin of the National University "Lviv Polytechnic". Series: Teoriia i praktyka budivnytstva, 627, 172-178. [In Ukrainian].

Pitsyshyn, B. S., \& Orel, V. I. (2009). Pidvyshchennia stiikosti pin za dopomohoiu natriikarboksymetyltselliulozy. Bulletin of the National University "Lviv Polytechnic". Series: Teoriia i praktyka budivnytstva, 655, 219-223. [In Ukrainian].

Povh, I. L., \& Chernyuk, V. V. (1986). Eksperimentalnoe issledovanie vliyaniya dobavok poliakril-amida na soprotivlenie diffuzorov. Inzh.-fizichesk. zhurn., 51(3), 357-361. [In Russian].

Povh, I. L., \& Chernyuk, V. V. (1989). Soprotivlenie konfuzorov pri turbulentnom techenii vodyi s dobavkami poliakrilamida. Inzh.-fizichesk. zhurn., 57(5), 709-712. [In Russian].

Raghupathi, P. Rao, \& Ramachandra, A. Rao. (1983). Flow between torsionally oscillating noncoaxial cylinders. Proceedings of the Indian Academy of Sciences (Math. Sc.), 92(1).

Uner Deniz, Ozgen Canan, \& Tosun Ismail. (1989). Flow of a powerlaw fluid in an eccentric annulus. SPE Drilling Engineering, 4(3), 269-272. https://doi.org/10.2118/17002-PA

White Scott, A (1989). Flow modification in the two-roll mill. Journal of Non-Newtonian Fluid Mechanics, 33(3), 325-341.

И. Ю. Попадюк, Б. С. Пицишин, В. И. Орел

Национальный университет "Львовская политехника", г. Львов, Украина

\section{УВЕЛИЧЕНИЕ ТРЕНИЯ В ПОТОКЕ ТЕЙЛОРА-КУЭТТА ПРИ ИСПОЛЬЗОВАНИИ НАТРИЙКАРБОКСИМЕТИЛЦЕЛЛЮЛОЗЫ}

Представлены результаты экспериментальных исследований влияния эксцентриситета ротора относительно статора и растворов карбоксиметилцеллюлозы на коэффициент трения в гидротормозе с регулируемым тормозным моментом. Кольцевой зазор между ротором с диаметром 113 мм и статором с диаметром 142 мм заполняли водными растворами карбоксиметилцеллюлозы с добавлением гидрокарбоната натрия для стабилизации. Массовые концентрации карбоксиметилцеллюлозы - 0,$5 ; 1,0 ; 2,0 ; 4,0 \%$, гидрокарбоната натрия - $0,2 \%$ от массы раствора. Кольцевой зазор между поверхностями цилиндров, который отвечал коаксиальному их расположению, трансформировался в замкнутый конфузорно-диффузорный при изменении положения внешнего цилиндра относительно внутреннего. Выявлена зависимость коэффициента трения от числа Рейнольдса, ширины промежутка между ротором и статором при их аксиальном расположении и концентрации водных растворов карбоксиметилцеллюлозы. С увеличением числа Рейнольдса наблюдалось уменьшение коэффициента трения для 
исследованных концентраций растворов карбоксиметилцеллюлозы. При постоянных значениях числа Рейнольдса с увеличением концентрации растворов карбоксиметилцеллюлозы получено увеличение коэффициента трения по сравнению с водой. При уменьшении ширины промежутка получено увеличение коэффициента трения для всех исследованных концентраций растворов карбоксиметилцеллюлозы. Полученные результаты указывают на возможность регулирования тормозного момента гидротормоза изменением эксцентриситета между ротором и статором и могут быть использованы при проектировании гидравлических тормозов с регулируемым тормозным моментом.

Ключевые слова: гидравлический тормоз; эксцентричные цилиндры; ротор; коэффициент трения; крутящий момент; число Рейнольдса.

I. Yu. Popadyuk, B. S. Pitshishin, V. I. Orel Lviv Polytechnic National University, Lviv, Ukraine

INCREASE IN FRICTION IN THE TAYLOR-COETTE FLOW USING SODIUM CARBOXYMETHYL CELLULOSE

The results of experimental investigations of the influence of the rotor eccentricity on the stator and the influence of the carboxymethyl cellulose solutions on the friction coefficient in the hydraulic brake with the control braking torque are presented. Hydraulic brakes are used in bench studies, because they are simple in design, have high energy intensity and can regulate the load and rotation of the shaft. When using hydraulic brakes, the power developed by the engine under study is spent on overcoming the forces of the hydrodynamic resistance of the friction of the rotor in the working fluid, heating it and converted into heat energy. In the experimental stand, the annular gap between the rotor with a diameter of $113 \mathrm{~mm}$ and a stator with a diameter of $142 \mathrm{~mm}$ was filled with water and aqueous solutions of carboxymethyl cellulose with the addition of sodium bicarbonate for stabilization. Mass concentrations of carboxymethyl cellulose were taken equal to $0.5 ; 1.0 ; 2.0 ; 4.0 \%$, sodium bicarbonate $-0.2 \%$ by weight of solution. The annular gap between the surfaces of the cylinders, which corresponded to their coaxial location, was transformed into a closed confuser-diffuser with a change in the position of the outer cylinder. It was also found that with increasing of angular velocity, the difference between the dimensionless torque for water and the aqueous solutions of carboxymethyl cellulose increases with a relative width of the gap equal to 1.0. The dependence of the coefficient of friction on the Reynolds number, on the width of the gap between the rotor and stator and on the concentration of aqueous solutions of carboxymethyl cellulose was found. As the Reynolds number increases, a decrease in the coefficient of friction for the investigated concentrations of solutions of carboxymethyl cellulose is observed. At constant values of the Reynolds number with an increase in the concentration of studied solutions of carboxymethyl cellulose, an increase in the coefficient of friction compared with water was obtained. With a decrease in the gap width, an increase in the friction coefficient was obtained for all the studied concentrations of carboxymethyl cellulose solutions. The obtained results indicate the possibility of adjusting the brake torque of the hydraulic brake by changing the eccentricity between the rotor and the stator and can be used in the design of the hydraulic brakes with the adjustable brake torque.

Keywords: hydraulic brake; eccentric cylinders; rotor; coefficient of friction; torque; the Reynolds number. 